\title{
A CONDIÇÃO DO PROFISSIONAL LIBERAL EM RELAÇÃO À CONTRIBUIÇÃO SINDICAL RECOLHIDA POR ORGANIZAÇÕES SINDICAIS DE PROFISSÕES LIBERAIS À LUZ DA CONSTITUIÇÃO FEDERAL ${ }^{1}$
}

\author{
Lilian Santa Lucia ${ }^{2}$
}

\begin{abstract}
RESUMO: Este estudo tem por objetivo dar solução para uma problemática sobre a qual até hoje muito pouco se debateu, qual seja, a constitucionalidade da exigência de contribuição sindical de profissionais liberais por organizações sindicais de profissões liberais. Ao fim da pesquisa, concluiu-se que o legislador constituinte não legitimou a exigência de contribuição sindical de qualquer profissional liberal, pois deixou de acrescer a previsão do art. 149 da CF "de interesse das categorias profissionais ou econômicas” a expressão "ou profissão liberal". A par disso, tem-se que as organizações sindicais de profissões liberais, uma vez que tiveram a sua atividade limitada a representação daqueles integrantes da categoria profissional diferenciada, de acordo com a Lei 7.316/85, não têm legitimidade para exigir contribuição sindical de profissionais não empregados.

PALAVRAS CHAVES: profissional liberal e contribuição sindical.
\end{abstract}

ABSTRACT: This study has for objective give a solution to the problematic who, until today, never been too much debated independent of the constitutionality of exigencies to syndical contribute of liberal professionals by syndical organizations of liberal professions. In the end of the search, was concluded that the constituent legislator doesn't legitimate the syndical contribution exigency of any liberal professional, because he doesn't increase the prevision of the article 149 of the federal constitution "of interest of the professional or economic categories" the expression "or liberal profession". Knowing that, the syndical organizations of liberal professionals not have legitimacy to require syndical contribution of professionals not employed because they have your activity limited by the representation of integrants of the differentiated professional category, according to the law 7.316/85.

KEY-WORDS: liberal professional and syndical contribution.

\section{INTRODUÇÃO}

Com o estabelecimento dos sindicatos em nosso ordenamento jurídico, foram surgindo normas que regulamentavam o sistema de custeio destas entidades.

Atualmente a contribuição sindical é a única cobrança compulsória dos sindicatos à totalidade da categoria que representam, uma vez que foi recepcionada pela Constituição Federal (CF) de 1988, em seu artigo (art.) 8º, inciso (inc.) IV - "independentemente da contribuição prevista em lei”-, bem como no art. 149.

Ocorre que, quando comparamos a redação do art. 149 da CF com o teor de dispositivos da CLT (Consolidação de Leis do Trabalho), dentre outros, os artigos 578 e 579, notamos que estes agregaram a destinação constitucional "interesse de categoria profissional ou econômica", o interesse de "profissão liberal”. Por decorrência, as entidades

\footnotetext{
${ }^{1}$ Síntese da Monografia de Graduaçao apresentada no Curso de Direito da Universidade Federal de Santa Maria, como requisito parcial para a obtenção do grau de Bacharel em Direito em dezembro de 2006.

${ }^{2}$ Graduada no Curso de Direito da UFSM. Pós-graduanda em Direito do Trabalho e Direito Previdenciário pela Faculdade de Direito de Santa Maria (FADISMA).

(C) 2007. Departamento de Direito da UFSM. Todos os direitos reservados.
} 
sindicais $^{3}$ que integram a Confederação Nacional de Profissões Liberais (CNPL) vêm cobrando contribuição sindical de todos os profissionais liberais, independentemente de serem empregados, empregadores ou autônomos.

Este artigo, assim, tem como objetivo perquirir a constitucionalidade da exigência de contribuição sindical de profissional liberal por organizações sindicais de profissões liberais. Ou seja, partindo de que a referida ampliação da finalidade constitucional inserida nas normas da CLT não foi recepcionada pela Constituição de 1988, pretendemos pesquisar a condição de profissionais liberais em relação à contribuição sindical exigida por entidades sindicais integrantes da Confederação Nacional de profissões liberais (CNPL).

Tal questão tem passado despercebida da comunidade jurídica, que, exceto as decisões superficiais dos Juízos Trabalhistas, não possui nenhuma manifestação específica na doutrina.

Por conta disso, mesmo sabendo do risco de equivocada conclusão, uma vez que não tivemos o amparo de autores de boa nota tratando especificadamente do assunto, resolvemos abordar o tema no intuito de aprofundar o debate bem como delimitar o alcance do art. 149 da CF.

\section{DESENVOLVIMENTO}

No que concerne à contribuição sindical, pacificou-se na doutrina e jurisprudência que se trata de modalidade de contribuição de interesse de categoria profissional ou econômica. Notamos, pois, que adotando a classificação qüinqüipartida dos tributos (imposto, taxa, contribuição de melhoria, empréstimo compulsório e contribuições especiais) a referida exação integra a espécie contribuição especial.

A propósito, Geraldo Ataliba explica:

O próprio sistema constitucional adota a classificação de tributos e faz derivarem consequiências do discernimento que estabelece entre as espécies e subespécies tributárias. Isto é: o texto constitucional consagra uma determinada classificação e atribui regimes jurídicos diferentes a serem aplicados às espécies tributárias. No próprio texto constitucional estão princípios e regras diferentes, e peculiares, aplicáveis com exclusividade - e relevantes efeitos - às diversas espécies e subespécies de tributos (1998 apud GAMA, [20__]).

Refere ainda o renomado jurista que:

\footnotetext{
${ }^{3} \mathrm{O}$ uso da expressão entidade sindical, ou organização sindical, abrange os três graus associativos, ou seja, elenca sindicatos, federações e confederações, como órgãos de primeiro, segundo e terceiro graus respectivamente. Como regra usual, aos sindicatos associam-se trabalhadores ou empregadores, individualmente considerados; às federações, filiam-se, em princípio, sindicatos; e às confederações, as federações.
} 
Conforme um tributo se configure inserto numa ou noutra categoria, as consequiências serão diferentes. No Brasil, é de fundamental importância proceder com rigor na tarefa de identificar as peculiaridades de cada espécie, porque a rigidez do sistema constitucional tributário (...) fulmina de nulidade qualquer exação não obediente rigorosamente aos moldes constitucionais estritos (ibid.).

Dentre as características que asseguram para a contribuição especial natureza jurídica específica, a principal nota está em ser instituída como instrumento para atuação em áreas pré-determinadas constitucionalmente. Ou seja, a CF indicou as finalidades que devem atingir.

A finalidade, como bem manifesta Luciano Amaro (2001, p. 110), “é posta pela Constituição como aspecto integrante do regime jurídico da figura tributária na medida em que se apresenta como condição, requisito, pressuposto ou aspecto do exercício legítimo (isto é, constitucional) da competência tributária".

Registramos que, quando se fala que tal tributo possui destinação, se está referindo à vinculação legal que tal tributo tem com o contribuinte. Nesse sentido, Hugo de Brito Machado afirma:

A contribuição social caracteriza-se como de interesse de categoria profissional
ou econômica quando destinada a propiciar a organização dessa categoria,
fornecendo recursos financeiros para a manutenção de entidade associativa.
Não se trata, é bom insistir neste ponto, de destinação de recursos arrecadados.
Trata-se de vinculação da própria entidade representativa da categoria
profissional ou econômica, com o contribuinte. O sujeito ativo da relação
tributária, no caso, há de ser a mencionada entidade (2001, p. 352) Na seqüência, ainda, sobre o contribuinte do tributo, o jurista esclarece que:

Em se tratando de contribuições de interesse de categorias profissionais ou econômicas, é razoável entender-se que o contribuinte deve ser a pessoa, física ou jurídica, integrante da categoria profissional ou econômica. Pessoa que não integra qualquer uma dessas categorias não deve ser compelida a contribuir no interesse das mesmas. (ibid., p. 357) (grifos nossos)

Os conceitos de categoria dispostos nos parágrafos do art. 511 da $\mathrm{CLT}^{4}$, conforme julgamento da Corte Suprema no Recurso em Mandado de Segurança 21.305-1, foram recepcionados pela ordem constitucional atual.

\footnotetext{
${ }^{4}$ Art. 511. É lícita a associação para fins de estudo, defesa e coordenação dos seus interesses econômicos ou profissionais de todos os que, como empregadores, empregados, agentes ou trabalhadores autônomos ou profissionais liberais exerçam, respectivamente, a mesma atividade ou profissão ou atividades ou profissões similares ou conexas.
}

$\S 1^{\mathrm{o}}$ A solidariedade de interesses econômicos dos que empreendem atividades idênticas, similares ou conexas, constitue o vínculo social básico que se denomina categoria econômica. 
Assim, da categoria econômica participam aqueles que empreendem atividades idênticas, similares ou conexas com interesses econômicos. Mais precisamente, da categoria econômica participam os empregadores.

Da categoria profissional participam os empregados na mesma atividade econômica, ou em atividades econômicas similares ou conexas.

Da categoria profissional diferenciada participam os empregados que exerçam profissões ou funções diferenciadas por força do estatuto profissional especial ou em consequiência de condições de vida singulares.

Logo, considerando que os profissionais liberais podem ser integrantes tanto da categoria profissional diferenciada, quando empregados, quanto da categoria econômica, quando empregadores, e, ainda, de nenhuma categoria, quando autônomos, não há como enquadrá-los indistintamente numa única entidade sindical.

Ademais, o texto constitucional é claro quando dispõe que a principal função do sindicato é a "defesa dos direitos e interesses coletivos ou individuais da categoria" (art. $8^{\circ}$, III), não sendo legitimado, salientamos, para defesa das categorias (sindicato misto, que representa empregador e empregado), ou de uma profissão liberal.

Ainda, a Constituição Federal de 1988 limitou o exercício da competência tributária da União a instituir contribuição com finalidade no interesse das categorias profissionais ou econômicas ${ }^{5}$.

Por oportuno, salientamos que as competências tributárias, ou seja, as faculdades para editar leis que criem, in abstrato, tributos, estão estabelecidas à exaustão na

$\S 2^{\circ}$ A similitude de condições de vida oriunda da profissão ou trabalho em comum, em situação de emprego na mesma atividade econômica ou em atividades econômicas similares ou conexas, compõe a expressão social elementar compreendida como categoria profissional.

$\S 3^{\circ}$ Categoria profissional diferenciada é a que se forma dos empregados que exerçam profissões ou funções diferenciadas por força de estatuto profissional especial ou em consequência de condições de vida singulares.

$\S 4^{\circ}$ Os limites de identidade, similaridade ou conexidade fixam as dimensões dentro das quais a categoria econômica ou profissional é homogênea e a associação é natural . (grifos nossos)

${ }^{5} \mathrm{CF}$, art. 149. Compete exclusivamente à União instituir contribuições sociais, de intervenção no domínio econômico e de interesse das categorias profissionais ou econômicas, como instrumento de sua atuação nas respectivas áreas, observado o disposto nos arts. 146, III, e 150, I e III, e sem prejuízo do previsto no art. 195, $\S 6^{\circ}$, relativamente às contribuições a que alude o dispositivo. (grifos nossos) 
Constituição Federal, de sorte que nenhuma outra norma que componha o nosso ordenamento jurídico possa alterá-la.

A Carta Magna, dessa forma, não cria tributos, mas apenas discrimina competências para que a União, Estado, Município e Distrito Federal venham a fazê-lo por meio de lei, em respeito ao princípio da legalidade tributária.

O tributo, nessa esteira, só será exigível após o advento da lei criadora, desde que ela não tenha violado os limites ao poder de tributar previstos, sobretudo, na Constituição.

Diante disso, é vedado à lei tributária alterar conceitos de outros ramos do direito, quando tenham sido utilizados para definir a competência tributária.

Esse entendimento, inclusive, inspirou o art. 110 do Código Tributário Nacional.

Art. 110. A lei tributária não pode alterar a definição, o conteúdo e o alcance de institutos, conceitos e formas de direito privado, utilizados, expressa ou implicitamente, pela Constituição Federal, pelas Constituições dos Estados, ou pelas Leis Orgânicas do Distrito Federal ou dos Municípios, para definir ou limitar competências tributárias.

Ocorre que, ao nos atermos aos termos que constam da lei ordinária, notamos que o legislador infraconstitucional permitiu às entidades sindicais a representação, e, por decorrência, a exigência de contribuição sindical, não apenas de uma categoria, profissional ou econômica, conforme competência limitada pelo texto constitucional, mas também de profissões liberais.

Destacamos dois artigos da CLT para verificar se é compatível com a Carta Mãe.

Dispõe o art. 578:

As contribuições devidas aos Sindicatos pelos que participem das categorias econômicas ou profissionais ou das profissões liberais representadas pelas referidas entidades serão, sob a denominação do "imposto sindical", pagas, recolhidas e aplicadas na forma estabelecida neste Capítulo.

Percebemos, na leitura deste artigo, que o legislador agregou algo substancialmente novo à finalidade limitada no art. 149 da $\mathrm{CF}$, interesse de categoria profissional ou econômica, ou seja, ampliou a destinação do tributo ao interesse de profissões liberais.

Já o art. 579, diz:

A contribuição sindical é devida por todos aqueles que participarem de uma determinada categoria econômica ou profissional, ou de uma profissão liberal, em favor do sindicato representativo da mesma categoria ou profissão ou, inexistindo este, na conformidade do disposto no art. 591.

Neste artigo, no reflexo à ampliação da finalidade do art. 578 antes referido, previu que é sujeito passivo da contribuição sindical todo profissional liberal, independentemente de ser empregado, empregador ou autônomo. 
O legislador constituinte poderia ter legitimado a exigência de contribuição sindical de qualquer profissional liberal, caso houvesse acrescentado à previsão do art. 149 da CF "de interesse das categorias profissionais ou econômicas" a expressão "ou profissão liberal". Mas assim não o fez. Com isso, é perfeitamente cabível a aplicação do princípio “inclusio unius alterius exclusio" (o que a lei não incluiu é porque desejou excluir).

Diante do exposto, a nosso ver, para a conciliação viável dos artigos $8^{\circ}$, inc. IV e 149, ambos da CF, entendemos que houve revogação parcial dos artigos 578 e 579 da CLT, dentre outros artigos de tal diploma infraconstitucional que permitam às entidades sindicais de profissões liberais a cobrança de contribuição sindical daqueles que participarem de profissões liberais (empregado, empregador, autônomo). Ou seja, aplicamos o princípio utille per inutille nom vitiatur (o útil não é viciado pelo inútil), aproveitando a parte compatível com a norma maior (contribuição sindical para participantes das categorias profissionais ou econômicas) e rejeitando a parte que não se adequou ao novo ordenamento constitucional (contribuição sindical para participantes das profissões liberais).

Por outro lado, aqueles profissionais que possuem os dois requisitos que o $\S 3^{\circ}$ do art. 511 da CLT exige - ser empregado e exercer profissão com estatuto profissional especial -, indubitavelmente participam de categoria profissional diferenciada.

Inclusive a Lei 7.316/85, no nosso entendimento, limita a representação das entidades sindicais de profissionais liberais àqueles vinculados à relação de emprego, in verbis:

Nas ações individuais e coletivas de competência da Justiça do Trabalho, as entidades sindicais que integram a Confederação Nacional das Profissões Liberais terão o mesmo poder de representação dos trabalhadores-empregados atribuído, pela legislação em vigor, aos sindicatos representativos das categorias profissionais diferenciadas.

Esse entendimento parece que foi acolhido pelo Ministro Eros Grau, no julgamento da ADI n 2522-DF, em 08.06.2006, in verbis:

$\mathrm{O}$ texto normativo atribui à $\mathrm{OAB}$ a função tradicionalmente desempenhada pelos sindicatos, ou seja, a defesa dos direitos e interesses coletivos ou individuais da categoria, com a ressalva de que a defesa desempenhada pela Ordem ampara todos os inscritos, não apenas os empregados, como o fazem os sindicatos. (grifos nossos)

Sabemos das particularidades no que tange aos advogados e do risco de relacionálos equivocadamente com outros profissionais liberais. No entanto, nesse caso, ao adotar a posição de que os sindicatos dos advogados defendem somente os empregados, acreditamos 
ser totalmente viável ampliá-la no sentido de que qualquer sindicato de profissão liberal defende somente os que são empregados ${ }^{6}$.

\section{CONCLUSÃO}

Ante o exposto, considerando que a contribuição sindical é destinada ao custeio da atividade de representação desenvolvida pela entidade sindical, bem como que as entidades sindicais de profissões liberais representam somente aqueles participantes da categoria profissional diferenciada, ou seja, profissionais liberais empregados, entendemos que somente estes são sujeitos passivos da contribuição sindical.

Os profissionais liberais empregadores podem ser representados por outros sindicatos, levando em conta sua principal atividade econômica, como por exemplo, atividades médicas e odontológicas, representação do sindicato de hospitais, clínicas e Casa de Saúde.

Já os autônomos, como não são a ninguém subordinados quando prestam serviços, assumem o risco da atividade, bem como negociam individualmente com o tomador de serviço. Por conta disso, um sindicato que a eles representasse não teria com quem negociar normas coletivas. E mais, caso resolvesse o autônomo fazer greve, não conseguiria fazer pressão aos tomadores de serviços, pois, diferentemente dos empregados, não tem assegurado o direito do tomador de serviços de não rescindir o contrato de trabalho, podendo tal livremente pactuar com outro autônomo. Nesse passo, os autônomos não precisam de representação sindical, e, por decorrência, não devem pagar a contribuição sindical.

\footnotetext{
${ }^{6}$ No que concerne à Ordem dos Advogados do Brasil (OAB), a jurisprudência está se pacificando no sentido de que não possui natureza jurídica de autarquia, diferentemente das demais entidades de fiscalização de classe. A natureza jurídica especial e única da OAB decorre de sua posição de colaborador do Poder Judiciário, conforme atesta o art. 133 (“o advogado é indispensável à administração da justiça”) e art. 93, I (estabelece que a OAB deve participar, em todas as fases, dos concursos públicos de provas e títulos, para ingresso da carreira da Magistratura), ambos da CF. Nesse viés, como a OAB é um órgão complementar e auxiliar do Poder Judiciário, não é possível subordiná-la ao Poder Executivo, como autarquia, pois violaria o princípio de independência e harmonia entre os poderes do Estado (art. $2^{\circ}, \mathrm{CF}$ ). Ainda, registramos que, diante da natureza intrínseca da $\mathrm{OAB}$, as contribuições recebidas pela entidade não possuem natureza tributária. (RESP 497.871-SC, RESP 449.760/SC; RESP 614.678-SC).

Quanto aos advogados, diferentemente dos demais profissionais liberais, nunca foram obrigados a pagar a contribuição sindical. O antigo Estatuto da OAB, Lei 4.215/63, fixava, no art. 143, que "o pagamento da contribuição anual à Ordem exclui os inscritos nos seus quadros de incidência obrigatória do imposto sindical." Na mesma esteira, o art. 47, da Lei 8906, estabeleceu que "o pagamento da contribuição anual à $\mathrm{OAB}$ isenta os inscritos nos seus quadros de pagamento obrigatório da contribuição sindical".
} 
Por fim, registramos que a doutrina e jurisprudência pátria, sem examinar a matéria em face dos limites constitucionais ao poder de tributar, e considerando apenas o art. $8^{\circ}$, $\mathrm{IV}$, in fine, da $\mathrm{CF}$, entendem que as entidades sindicais de profissões liberais possuem legitimidade de exigir contribuição sindical de todos os profissionais liberais (empregadores, empregados e autônomos). No entanto, conforme exposto, temos outro juízo.

\section{REFERÊNCIAS BIBLIOGRÁFICAS}

AMARO, Luciano. Direito Tributário Brasileiro. 10. ed. São Paulo: Saraiva, 2004.

BORTOLOTTO, Rudimar Roberto. Os aspectos da representatividade no atual direito sindical brasileiro. São Paulo: LTr, 2001.

BRASIL. CLT acadêmica. Obra coletiva de autoria da Editora Saraiva com a colaboração de Antonio Luiz de Toledo Pinto, Márcia Cristina Vaz dos Santos Windt e Lívia Céspedes. 3. ed. São Paulo: Saraiva, 2005.

Constituição Federal, Código Comercial e Código Tributário. Organizado por Nylson Paim de Abreu Filho. Porto Alegre: Verbo Jurídico, 2004.

Superior Tribunal de Justiça. Recurso Especial n 449.760-SC (2002/0086730/4); Relator: Ministro Franciulli Netto. Segunda Turma. Julgamento: 25/11/2003. Disponível em:<www.stf.gov.br>. Acesso em: 17 ago. 2006.

Superior Tribunal de Justiça. Recurso Especial n 614.678-SC (2003/0226418-9);

Relator: Ministro Teori Albino Zavascki. Primeira Turma. Julgamento: 20/05/2004. Disponível em:<www.stf.gov.br>. Acesso em: 17 ago. 2006.

Supremo Tribunal Federal. Ação Direta de Inconstitucionalidade n ${ }^{\circ}$ 2.522-8/DF;

Relator: Ministro Eros Grau. Pleno. Julgamento: 08/06/2006. Disponível em:<www.stf.gov.br>. Acesso em: 16 ago. 2006.

Supremo Tribunal Federal. Recurso em Mandado de Segurança n ${ }^{\circ}$ 21.305-1/DF;

Relator: Ministro Marco Aurélio. Pleno. Julgamento: 17/10/1991. Disponível em:<www.stf.gov.br>. Acesso em: 16 ago. 2006.

CARRAZA, Roque Antônio. Curso de direito constitucional tributário. 3.ed. São Paulo: Revista dos Tribunais, 1991.

CHIARELLI, Carlos Alberto. O trabalho e o sindicato: evolução e desafios. São Paulo: LTr, 2005. 
COELHO, Sacha Calmon Navarro. Curso de direito tributário brasileiro. 8. ed. Rio de Janeiro: Forense, 2005.

CORTEZ, Julpiano Chaves. O advogado empregado. São Paulo: LTr, 2000.

GAMA, Evandro Costa. As contribuições sociais de seguridade social e a imunidade do art. 149, $\S \mathbf{2}^{\circ}$, I, da Constituição Federal. Disponível em: <http://www.sinprofaz.org.br/CEJ/Trabalhos/EvandroCostaGama.htm>. Acesso em: 15 jun. 2006.

LEBRE, Eduardo Antonio Tempony. Sistema jurídico de custeio dos sindicatos. São Paulo: Iglu, 1997.

LEI N ${ }^{\circ}$ 7.316, de 28 de maio de 1985. Disponível em:<www.planalto.gov.br〉. Acesso em: 22 ago. 2006.

MACHADO, Hugo de Brito. Curso de direito tributário. 19. ed. São Paulo: Malheiros, 2001.

MOTTA, Sylvio. Direito Constitucional: teoria, jurisprudência e 1.000 questões. 18. ed. Rio de Janeiro: Elsevier, 2006.

RAMOS FILHO, Irineu. Enquadramento sindical: o conceito de categoria diferenciada. Disponível em: http://www.senge-sc.org.br/enquadramentosindical.htm>. Acesso em: 15 jun. 2006.

RUSSOMANO, Mozart Victor. Princípios gerais de direito sindical. 2. ed. Rio de Janeiro: Forense, 2002.

UNIVERSIDADE FEDERAL DE SANTA MARIA. Estrutura e Apresentação de Monografias, Dissertações e Teses: MDT / Universidade Federal de Santa Maria. Pró Reitoria de Pós-Graduação e Pesquisa. 6a edição. Santa Maria: Ed. da UFSM, 2005. 